\title{
Nutrition of the elderly with atherosclerosis
}

\author{
Tilen Dolinar, Saša Kastelic, Andreja Kvas \\ University of Ljubljana: Faculty of Health Sciences, Ljubljana, Slovenia \\ tilen.dolinar@gmail.com; sasakast@gmail.com; andreja.kvas@zf.uni-lj.si
}

\begin{abstract}
Introduction and purpose: Atherosclerosis is a disease of the vascular wall of the aorta and the middle and large arteries of the muscular and elastic type. It is an advanced process that can remain without symptoms and signs for a long time, and in the advanced stage it is manifested by one or more manifestations, such as coronary heart disease, stroke or peripheral vascular disease. It can begin in childhood and progress with age, but it is also accelerated by risk factors. The main risk factors include hypercholesterolemia, hyperlipidemia and increased concentration of low-density lipoproteins, arterial hypertension, obesity, diabetes, smoking, lack of physical activity. Although the developed atherosclerotic changes are irreversible, we can influence the rate of disease progression, especially with a healthy lifestyle, ie a healthy balanced diet and regular physical activity. Content presentation: Atherosclerosis is a disease affecting the vascular aortic wall and the middle and large elastic and muscular arteries. It is a progressive condition whose symptoms and signs may not occur for a longer period of time while the progressive stage may manifest itself via one or several of its manifestations, including coronary artery disease (CAD), a brain stroke, or Peripheral arterial disease (PAD). The disease may develop in childhood and progress with age, although the risk of the latter may be dramatically increased by certain risk factors. The main risk factors include hypercholesterolemia, hyperlipidemia and increased concentration of low-density lipoproteins, arterial hypertension, obesity, diabtes, smoking, and a lack of physical activity. Although atherosclerosis causes irreversible changes, one can significantly influence the progression of the latter with a healthy, balanced diet and regular physical exercise. Conclusions: The occurrence of atherosclerosis is associated with many factors that we can influence and factors that we cannot influence ourselves. In our article, we focused mainly on
\end{abstract}


the impact of proper diet. In reviewing the articles, we found that the authors mention a number of diets, such as the DASH diet, the TLC diet, the Mediterranean diet. The most appropriate diet for patients with atherosclerosis is one that includes foods from all groups of the food pyramid in moderation. An important factor is prevention and awareness of people, as cardiovascular disease as a result of atherosclerosis is one of the main factors of premature morbidity and mortality in the developed world, and thus also the financial burden of the health system.

Keywords: aging, cardiovascular diseases, physical activity, prevention

\section{Introduction}

Atherosclerosis is a disease of the vascular wall of the aorta and the middle and large arteries of the muscular and elastic type. It is an advanced process that can remain without symptoms and signs for a long time, and in the advanced stage it is manifested by one or more manifestations, such as coronary heart disease, stroke or peripheral vascular disease. It can begin in childhood and progress with age, but it is also accelerated by risk factors. The main risk factors include hypercholesterolemia, hyperlipidemia and increased concentration of low-density lipoproteins, arterial hypertension, obesity, diabetes, smoking, lack of physical activity.

Although the developed atherosclerotic changes are irreversible, we can influence the rate of disease progression, especially with a healthy lifestyle, ie a healthy balanced diet and regular physical activity (Petek Šter, 2017).

\section{Structured sections}

Atherosclerosis is a disease affecting the vascular aortic wall and the middle and large elastic and muscular arteries. It is a progressive condition whose symptoms and signs may not occur for a longer period of time while the progressive stage may manifest itself via one or several of its manifestations, including coronary artery disease (CAD), a brain stroke, or Peripheral arterial disease (PAD) (American Heart Association, 2017). The disease may develop in childhood and progress with age, although the risk of the latter may be dramatically increased by certain risk factors. The main risk factors include hypercholesterolemia, hyperlipidemia and increased concentration of low-density lipoproteins, arterial hypertension, obesity, diabtes, smoking, and a lack of physical activity (NIJZ, 2014).

The Mediterranean-type diet is primary and secondary prevention of Cardiovascular Disease. It may be considered not one specific diet, but rather a collection of eating habits traditionally followed by people bordering the Mediterranean sea and consisting of a plant-centered diet with high intakes of vegetables and fruits, whole-grain cereals, extra-virgin oil, nuts, moderate consumption of fish and poultry, low intake of dairy products, red meat, sweets and 
moderate consumption of red wine for usual drinkers. The Scientific Advisory Committee of the American Heart Association stated that the Mediterranean-style diet has impressive effects on Cardiovascular Disease. Atherosclerosis is one of the most important risk factors for the development of Cardiovascular Disease. Thus, several pharmacological strategies have been used to decrease or prevent the development of atherosclerosis. Interestingly, in recent years several studies have emphasized the role of several dietary nutrients and bioactive compounds in the mechanisms of the processes around the plaque formation. Nutrients such as saturated fatty acid and trans-fatty acids, among others, are associated with an increase in the development of atherosclerosis. On the other hand, nutrients such as soy, omega-3 fatty acids, several vitamins, and polyphenols reduce or attenuate the appearance of atherosclerotic lesions. The activity of these compounds is associated with a reduction in the inflammatory response, in the antioxidant capacity to prevent oxidation of LDL particles, leukocyte migration, adhesion molecules, in the viability of VSMCs and reduction in blood pressure among others (Torres, Guevara-Cruz, 2015; Velázquez-Villegas and Tovar, 2015).

Nutrition is far more important in stroke risk than most physcians suppose. Healthy lifestyle choices reduce the risk of stroke by $80 \%$. A Cretan Mediterranean diet, high in olive oil, whole grains, fruits, vegetables and legumes, and low in cholesterol and saturated fat, can reduce stroke by $40 \%$ or more in high-risk patients. The role of the intestinal microbiome in cardiovascular risk is emerging. High levels of toxic metabolites produced by intestinal bacteria from meat (particularly red meat) and egg yolk are renally excreted. Patients with renal impairment, including the elderly, should limit red meat and avoid egg yolk, as should other patients at high risk of stroke. Salt intake should be limited to 2-3 grams per day. Metabolic B12 deficiency is common and usually missed. It has serious neurological consequences, including an increase in the risk of stroke. It now clear that B vitamins to lower homocysteine reduce the risk of stroke, but we should probably be using methylcobalamin instead of cyanocobalamin (Spence, 2019). Several conditions associated with the development of cardiovascular disease (CVD) such as diabetes, obesity, hypertension, and dyslipidemia are known to be modifiable by changes in lifestyle. Among lifestyle factors, our diet, including both the nutritional quality and our acquired eating patterns, constitutes a major target of CVD prevention strategies. Eating patterns are highly dependent on cultural, social and psychological determinants, as people integrate them into their daily life routines. A particular habit that might have a significant effect on CVD health is breakfast consumption, as it is associated with factors such as satiety, daily energy intake (EI), metabolic efficiency of the diet, and appetite regulation. A number of studies have reported associations between the habit of omitting breakfast and increased cardiometabolic health markers, including obesity, diabetes and unfavorable lipid profile. Although there are some studies linking skipping breakfast with coronary heart disease risk, to the best of our knowledge, 
no studies have investigated the association with this dietary habit on the presence of subclinical atherosclerosis. The aim of our study was to characterize the association between different breakfast patterns and CVD risk factors, and in particular, whether regularly skipping breakfast is associated with subclinical atherosclerosis, by investigating the presence of atherosclerotic plaques in the carotid arteries, aorta, and iliofemoral arteries or coronary artery calcium, in a population with no previous history of CVD (Spence, 2019).

Clinical studies report that consuming a high-calorie meal in the morning would result in a significant decrease in fasting glucose and insulin, as well as reduced plasma ghrelin concentrations, a hormone associated with food perception, leading toward lower energy foods preference. Moreover, studies linking breakfast consumption with overall diet quality and regulation of appetite, reported that not only micronutrient-rich breakfast but the morning meals in general were potentially satiating and had a beneficial effect on appetite regulation, which would help to balance the energy intake throughout the day and prevent overeating and subsequent obesity. Considering the importance of regular breakfast consumption for primary CVD prevention, our findings are important for health professionals and might be used as an important key, and simple message for lifestyle-based interventions and public health strategies, as well as informing dietary recommendations and guidelines (Spence, 2019).

Skipping breakfast could serve as a marker of unhealthy dietary and lifestyle behavior and is associated with the presence of noncoronary and generalized atherosclerosis independent of conventional CVD risk factors in a sample of middle-aged asymptomatic individuals. Our findings highlight the message of the importance of healthy eating, including an energetic breakfast (Uzhova, et.al., 2017).

Evidence of interaction between genetic markers and dietary components has helped shed light on the inconsistencies that have been reported between diet-related studies and sometimes genetic analyses among different populations. The knowledge from gene-environment (diet) interactions will enable more effective and specific interventions for CVD prevention based on "personalized" nutrition. It is important to emphasize, however, that although many published investigations often indicated strong nutrientgene interactions that underlie variability of phenotypes, with nutrient intake potentially modulating risk factors of CVD, it is difficult at this time to apply these data to clinical practice. Indeed each of these nutrigenetic studies considered individually only one or at most two gene variants, neglecting the possible global interactions between a wide array of gene variants with different nutritional interactions. Nutrigenetics and nutrigenomics are still in their infancy with respect to cardiovascular disease prediction and therapy! The road of personalized medicine requires much more robust and sophisticated characterization of the functional implications of a growing set of new polymorphisms and CVD risk factors, supported by well-controlled dietary intervention studies that yield highly consistent results. Atherosclerotic CVD is as much a metabolic as it is an in- 
flammatory disease. The power of nutrigenetics and nutrigenomics can be further enhanced with the coapplication of metabolomics, another rapidly emerging discipline. Management and prevention of CVD will benefit tremendously from personalized medicine including individualized nutritional therapy. The public health implications of nutritional therapy are enormous. Integration of the progress in the omics, such as metabolomics, lipidomics, transcriptomics, and proteomics, coupled with advances in nutrigenomic and nutrigenetic research will make personalized medicine a reality. In the meantime, nutritionists, medical practitioners and genetic counselors need to embrace the new nutrigenetics/nutrigenomics revolution to help bring the nutritional component of preventive medicine from the dangerous stage of "generalization“ toward the new era of „personalized medicine“ (Merched and Chan, 2013).

Atherosclerosis, which causes approximately half of all deaths of adults over age 60 in industrialized nations, is a pandemic among inappropriately nourished and/or physically hypoactive children, adolescents, and adults world wide. Although nowadays statins are widely prescribed to middle age and elderly adults with high blood lipid levels as pharmacological prevention for the late complications of atherosclerosis, from a critical point of view statins seem not to solve the problem, especially when compared with certain natural ingredients of our nutrition like micronutrients as alternative strategy. Statin ingestion is associated with lowering of serum cholesterol and low-density lipoprotein concentrations; some prospective studies have shown statistical associations with subsequent modest reduction of mortality from cardiovascular disease. However, specific biochemical pathways and pharmacological roles of statins in prevention of atherosclerosis, if any, are unknown. Moreover, there have been no systematic cost-benefit analyses of life-style prophylaxis versus statin prophylaxis versus combined life-style plus statin prophylaxis versus neither life-style nor statin prophylaxis for clinically significant complications of cardiovascular diseases in the elderly. Further, in the trials of effectiveness statins were not compared with management of nutrition, which is the most appropriate alternative intervention. Such studies seem to be important, as the ever increasing world population, especially in developing countries, now demand expensive statins, which may be unaffordable for mitigating the pandemic. Studies of this kind are necessary to identify more precisely those patients for whom cardiovascular benefits will outweigh the risks and costs of the statin treatment in comparison with nutritional interventions.

Against the background of the current pathogenetic concept of atherogenesis some of its possible risk factors, particularly the roles of cholesterol and homocysteine, and the effects of statins versus nutritional (micronutrients) interventions in prevention and treatment of the disease are discussed. The prevailing opinion that serum cholesterol as a mediator of the disease is increased by eating saturated fats and decreased by eating polyunsaturated fats is being challenged. Evidently, the beneficial effects of statins in atherosclerosis are not mainly due to its cholesterol lowering effect, rather than to its "pleiotropic ef- 
fects". Other pathogenetic factors in atherosclerosis are involved, like inflammatory and immunologic processes, that can be modulated by statins as well as by other drugs or by the Mediterranean-style nutrition and by micronutrients (folate, B-vitamins) (Gebbers, 2007).

Some recent published studies indicate again the marked clinical benefit of the ,Mediterranean nutrition' on cardiovascular function, including that of the elderly, which is associated with improved endothelial function in persons with metabolic syndrome. If we want to make the best of what common micronutrients and statins may offer in the prophylaxis of atherosclerosis, we should try to learn more about how to assess the positive effects of statins against their potential toxic risks in individual patients. Additionally, titrating lipid-lowering therapy to reduce LDL cholesterol to very low levels by statins can be difficult, costly, is not without risk and no solid evidence appears to support this recommendation of the National Cholesterol Education Program (Gebbers, 2007).

The potential effect of reducing the intake of industrially produced trans fatty acids on the incidence of coronary heart disease in the United states was calculated. The authors estimated on the basis of reported relations between trans fat intake and coronary heart disease events in prospective studies 10\% to $19 \%$ of coronary heart disease events could be averted by reducing the intake of trans fat. Thus, given the 1.2 million annual myocardial infarctions and deaths from coronary heart disease in the United States, near-elimination of industrially produced trans fats might avert between $72,000(6 \%)$ and 228,00o (19 \%) coronary heart diseases each year (Gebbers, 2007).

The unequivocal beneficial effects of long term caloric restriction on the blood pressure, the ratio of cholesterol/HDL-cholesterol, and the body mass index (BMI), which have been demonstrated recently, must carry some especially important lessons for public health and educational policies in our obesity-ridden, low exertion, industrialized societies, which should surely be at least as useful to us in the long run as is the ongoing education of our affluent population about the availability and cost of prophylactic statins. A recently published hypothesis indicates the possible fact that statins are analogues of vitamin D, since several effects of statins match well with those of that vitamin particularly the anomalous results, such as unexpected benefits of statins like the modulation of inflammations and immune states.

Nowadays, we have to face our dependence on results of studies sponsored by the industry, particularly we have become too dependent on manufacturers as the predominant source of our scientific knowledge about the effects of medications (Gebbers, 2007).

With pharmaceutical costs increasing faster than most other health care expenditures, we require studies that will meet the needs of evidence-based presriptions and treatments and not just the needs of the pharmaceutical industry. These trials must not only be conducted involving combination thera- 
pies of the company's own products or the test drug against a placebo but rather against nutritional regimens. The conduct of such equivalence or non-inferiority studies imposes markedly higher methodological demands compared with traditional studies to prove the superiority of a treatment vs. placebo or standard therapy. It is not a question of whether we can afford to pay for our own drug and nutritional trials; it is increasingly evident that we cannot afford not to do so (Gebbers, 2007).

\section{Conclusions}

The occurrence of atherosclerosis is associated with many factors that we can influence and factors that we cannot influence ourselves. In our article, we focused mainly on the impact of proper diet. In reviewing the articles, we found that the authors mention a number of diets, such as the DASH diet, the TLC diet, the Mediterranean diet. The most appropriate diet for patients with atherosclerosis is one that includes foods from all groups of the food pyramid in moderation.

An important factor is prevention and awareness of people, as cardiovascular disease as a result of atherosclerosis is one of the main factors of premature morbidity and mortality in the developed world, and thus also the financial burden of the health system (Benedičič, 2016).

\section{References}

AMERICAN HEART ASSOCIATION, 2017. What is cardiovascular disease? [viewed 15 March 2021]. Available from: https://www.heart.org/en/ health-topics/consumer-healthcare/what-is-cardiovascular-disease.

BEDENČIČ, M., 2016. Prehrana. Živeti z aterosklerozo: Priročnik za bolnike s koronarno boleznijo in drugimi oblikami ateroskleroze [online]. Nacionalni inštitut za javno zdravje, pp. 37-40. Available from: http://skupajzazdravje.nijz.si/media/ziveti.z.aterosklerozo.pdf.

GEBBERS, J., 2007. Atherosclerosis, cholesterol, nutrition, and statins - a critical review. German Medical Science, vol. 5, ISSN 1612-3174.

MERCHED, A. J., \& CHAN, L., 2013. Nutrigenetics and Nutrigenomics of Atherosclerosis. Current Atherosclerosis Reports, vol. 15, no. 6.

NIJZ, 2014. Srčno-žilne bolezni [online]. [viewed 15 March 2021]. Available from: https://www.nijz.si/sl/srcno-zilne-bolezni.

PETEK ŠTER, M., 2017. Preventivni pregled $\mathrm{z}$ oceno tveganja za bolezni srca in ožilja. Izvajanje integrirane preventive kroničnih nenalezljivih bolezni $\mathrm{v}$ referenčnih ambulantah družinske medicine: Priročnik za zdravnike družinske medicine [online]. Ljubljana: NIJZ, pp. 58 - 62. [viewed 15 March 2021]. Available from: http://skupajzazdravje.nijz.si/media/splet-. zdm.prirocnik.pdf.

SPENCE, J., 2019. Nutrition and Risk of Stroke. Nutrients, vol. 11 no.3, pp. 647. 
TORRES, N., GUEVARA-CRUZ, M., VELÁZQUEZ-VILlEGAS, L. A., \& TOVAR, A. R., 2015. Nutrition and Atherosclerosis. Archives of Medical Research, vol. 46 no. 5, pp. 408-26.

UZHOVA, I., FUSTER, V., FERNÁNDEZ-ORTIZ, A., ORDOVÁS, J. M., SANZ, J., FERNÁNDEZ-FRIERA, L.,PEÑALVO, J. L., 2017. The Importance of Breakfast in Atherosclerosis Disease. Journal of the American College of Cardiology, vol.7o, no. 15, pp.1833-42. 